\title{
Molecular Research Progress on Xishuangbanna Cucumber (Cucumis sativus L. var. Xishuangbannesis Qi et Yuan): Current Status and Future Prospects
}

\author{
Hesbon Ochieng Obel $\left.{ }^{1}{ }^{(}\right)$, Chunyan Cheng ${ }^{1}$, Zhen Tian ${ }^{1}$, Ji Li ${ }^{1}$, Qunfeng Lou ${ }^{1} \oplus$, Xiaqing Yu ${ }^{1}\left(\mathbb{D}\right.$, Yuhui Wang ${ }^{1}{ }^{(}$, \\ Joshua Otieno Ogweno ${ }^{2}$ and Jinfeng Chen ${ }^{1, * \mathbb{D}}$ \\ 1 State Key Laboratory of Crop Genetics and Germplasm Enhancement, College of Horticulture, \\ Weigang Campus, Nanjing Agricultural University, Nanjing 210095, China; 2019204059@njau.edu.cn (H.O.O.); \\ Chunyancheng@njau.edu.cn (C.C.); 2015204016@njau.edu.cn (Z.T.); liji1981@njau.edu.cn (J.L.); \\ qflou@njau.edu.cn (Q.L.); xqyu@njau.edu.cn (X.Y.); 2020050@njau.edu.cn (Y.W.) \\ 2 Department of Crops Horticulture and Soil Science, Faculty of Agriculture, Njoro Campus, \\ Egerton University, Nakuru City 20115, Kenya; jogweno@egerton.ac.ke \\ * Correspondence: jfchen@njau.edu.cn; Tel.: +86-(139)-5172-2067
}

\section{check for} updates

Citation: Obel, H.O.; Cheng, C.; Tian, Z.; Li, J.; Lou, Q.; Yu, X.; Wang, Y.; Ogweno, J.O.; Chen, J. Molecular Research Progress on Xishuangbanna Cucumber (Cucumis satious L. var. Xishuangbannesis Qi et Yuan): Current Status and Future Prospects. Agronomy 2022, 12, 300. https:// doi.org/10.3390/agronomy12020300 Academic Editors: Sophie Parks and Domenico Ronga

Received: 23 December 2021

Accepted: 18 January 2022

Published: 25 January 2022

Publisher's Note: MDPI stays neutral with regard to jurisdictional claims in published maps and institutional affiliations.

Copyright: (C) 2022 by the authors. Licensee MDPI, Basel, Switzerland. This article is an open access article distributed under the terms and conditions of the Creative Commons Attribution (CC BY) license (https:// creativecommons.org/licenses/by/ $4.0 /)$.

\begin{abstract}
The Xishuangbanna (XIS) cucumber is an important botanical variety, accumulating high levels of $\beta$-carotene $(700 \mu \mathrm{g} / 100 \mathrm{~g})$ in the endocarp of mature fruit compared with normal green/white flesh types $(25-50 \mu \mathrm{g} / 100 \mathrm{~g}$, fresh weight). $\beta$-carotene is an essential precursor of provitamin A synthesis required for human health, thus XIS cucumber is an appealing germplasm for vitamin A breeding programs. In this review, we highlighted the molecular research progress of XIS cucumber as well as the bottlenecks undermining its utilization in genetic breeding. The XIS cucumber was first reported in 1983; thereafter, the literature on XIS cucumber was sporadic until 2012 and 2013 following QTL mapping of the Ore gene and subsequent cloning of the CsaBCH1 gene, respectively. Whereas QTL mapping studies underlying its flowering time and fruit quality related traits have been reported, fine mapping of their candidate genes remains unknown. Cucumber fruits are mainly consumed at fresh immature stage; however, XIS cucumber accumulates $\beta$-carotene at mature fruit state, thus limiting the utilization of $\beta$-carotene derived from it. In our opinion, we believe that the production and commercialization of immature orange-fleshed cucumber would gain wider acceptance among consumers. Additionally, we highlighted a comprehensive breeding strategy, precisely for enhanced $\beta$-carotene accumulation based on prior studies of XIS cucumber coupled with those from other crops. In MAS, we proposed schematic molecular backcross breeding strategy using lines possessing both ore and fft 1.1 loci. This review, therefore, provides insights of XIS cucumber research and opportunities for further genetic breeding.
\end{abstract}

Keywords: Xishuangbanna cucumber; molecular breeding; orange-fleshed; $\beta$-carotene

\section{Introduction}

Cucumber (Cucumis sativus L.) is an important and popular vegetable of the Cucurbitaceae family. It is reported to be one of the earliest vegetables to be domesticated from wild Indian C. s var. Hardwickii [1] and its site of domestication by man could be dated back as far as 5000 years ago [2,3]. Cucumber was first cultivated in India and then later spread eastwards to China and westwards to Europe about 2000 and between 700 and 1500 years ago, respectively. The Europeans eventually spread cucumber to North America and Africa in the 1400s [3,4]. Cucumber is mostly grown for its soft fruits and is eaten in raw fresh form, cooked as a vegetable or pickled when immature [5,6]. Consumed fresh or processed, cucumber is regarded for its special flavor and its high-water content $(95 \%$ water). Its high-water content (about 95\%) makes it ideal to promote hydration during hot sunny days. The nutrient availability per $100 \mathrm{~g}$ fresh weight of cucumber contains energy 
(12-15 cal), protein (0.6-0.65 g), total lipids (0.1-0.11 g), carbohydrates (2.2-3.63 g), calcium (14-16 mg), iron (0.28 mg-0.3), vitamin C (2.8-12 mg), and vitamin A ( $\beta$-carotene, $1.125-5$ $\mu \mathrm{g})$, as well as other vitamins such as vitamin K, B6, B12, thiamine, niacin, flavonoids, and triterpenes, which provide antioxidants and anti-inflammatory substances [7-9].

The semi-wild Xishuangbanna cultivar (C. sativus var. xishuangbannesis, XIS hereafter) is unique based on their pedigree exhibiting orange-fleshed (endocarp) fruit at full seed maturity, signifying an abundance of $\beta$-carotenes just like melon, squash, and pumpkin [10,11]. The XIS cucumber is highly outcrossing, and thus is readily intercrossed to the common cultivated cucumber, sharing the same chromosome number $(2 n=2 x=14)$. Its fruits are eaten boiled or raw during different stages of maturity $[12,13]$. $\beta$-carotene not only acts as a precursor to pro-vitamin A synthesis, which is essential for human health, but also contributes to the fruit flesh color. Flesh color is one of the most important traits of fruits and vegetables that impacts positively on consumer's choice of food products. The flesh color type is attributed to different chlorophyll and carotenoid accumulations in fruits [14]. Low uptake of carotenoid-rich food results in vitamin A deficiency. Vitamin A deficiency is one of the most serious health issues in many countries, resulting in irreversible blindness. It is among the key pillars in the fight against malnutrition, commonly referred to as 'hidden hunger", ravaging the ever-increasing world population [15]. This situation has prompted researchers to attempt the biofortification of plant-derived foods including pro-vitamin A carotenoids (mainly $\beta$-carotene), which led to the birth of "golden" crops. Additionally, a variety of vegetables such as carrot and orange-fleshed sweet potato are naturally rich in $\beta$-carotene content and their improvement contributes to the pool of nutritional status. While high $\beta$-carotene cucumber may not contribute significantly to the vitamin A status among the consumers globally owing to its limited growing localities, consumption of carotenoid-rich XIS cucumber in regions where it is grown and marketed can contribute to the reduction in vitamin A deficiency and provision of health benefits required in the human body system [16].

The objective of this review is to provide research progress and the current status of the novel orange-fleshed cucumber and pinpoint bottlenecks undermining diversifying selection for genetic improvement. We also highlighted possible research undertakings for the traits of unknown regulatory mechanisms. Through the findings of the previous studies, involving XIS cucumber and the XIS derived lines, this review thus provides insights into orange-fleshed cucumbers and future research potentials. XIS cucumber, which originated in Yunnan province in China, was first brought to the attention of horticulturists in 1983 and has since been under investigations. Quantitative trait loci conferring fruit quality characteristics including $\beta$-carotene content, fruit size, fruit number, and fruit weight have been molecularly tagged. Based on the findings, XIS cucumber provides novel alleles that can be used for cucumber genetic improvement. We hope that this review coupled with the highlighted key research directions proposed herein will shape the genetic research improvement program of orange-fleshed cucumber.

\section{Chronological Perspective of Orange-Fleshed XIS Cucumber Discovery and Development}

XIS is a Chinese landrace, an accession from mountainous Xishuangbanna region of Yunnan Province in Southwest China, the area bordering Myanmar [12]. XIS cucumber was first described in 1983 [17]; thereafter, it drew the attention of the researchers, especially those interested in cucurbitaceous crops owing to its unique characteristics. Growing in a tropical warm and humid climate above $1000 \mathrm{~m}$ altitude, this form of cucumber has long been cultivated by the Jinuo, Hani, and Aini ethnic groups of China, Laos, and Vietnam, who call it 'Shihuo' [10].

A preliminary investigation of the orange flesh trait of XIS cucumber in 1991showed that a dominant genetic factor influences the orange-flesh color [18]. However, three years later (1994) Navazio [19] used a recessive two gene model to explain segregation in $\mathrm{F}_{2}$ progeny $(\mathrm{n}=46)$ resulting from a cross between 'SMR18' and XIS. In 1997, Simon and 
Navazio [16] developed XIS derivatives in U.S. pickling backgrounds that express orange fruit flesh pigmentation at maturity. This consisted of the development of early orange mass (EOM) 400, 402, and late orange mass (LOM) 404 from crosses between U.S. pickling cucumber and orange fruited XIS cucumber. Internal (mature and immature) fruit color was orange in 70-90 percent of the EOM 400 and EOM 402 plants in 1994, with yellow in the remaining samples. Plants with dark orange mature fruit color were slightly more prevalent in EOM $402(15 \%)$ than in EOM 400 (5\%); however, yellow immature fruit color was also slightly more common in EOM $402(30 \%)$ than in EOM $400(5 \%)$. However, the molecular mechanisms linked to early $\beta$-carotene accumulation of orange mass in EOM 402 or EOM400 remains unknown.

In 2009, a genetic study involving two genetic linkage maps constructed with the markers of random amplified polymorphic DNA (RAPD), sequenced characterized amplified region (SCAR), simple sequence repeats (SSR), Expressed sequence tag (EST), single nucleotide polymorphism (SNP), amplified fragment length polymorphism (AFLP), and (sequence specific amplification polymorphism (SSAP) was reported [20].These genetic linkage maps defined a common collinear region containing four molecular markers (3 dominant and 1 codominant) on linkage group (LG) LG6 in Map 1 and LG3 in Map 2. The regions contained QTL associated with orange mesocarp (mc6.1/ec6.1) and endocarp (mc3.1/ec3.1) in Map1 and Map2, respectively. Two pairs of allelic genes were found to be responsible for the yellow mesocarp, while a single recessive gene controls $\beta$-carotene in the endocarp as reported in 2010 [21] However, there are limited findings on cucumber flesh color at the molecular level. Through the United States department of Agriculture, a high $\beta$-carotene $(7.5 \mu \mathrm{g} / \mathrm{g})$ cucumber line EOM 402-10, was released in 2011 but it was still maintained for research purposes only [22].

In 2012, an inheritance and mapping of the gene controlling quantity of $\beta$-carotene at mature fruit stage was reported [23]. To identify the genetic locus controlling $\beta$-carotene content in XIS cucumber, bulk segregant analysis (of 124 RIL-F 7 population was applied and orange endocarp (Ore) gene controlling quantity of $\beta$-carotene identified to be located between SSR07706 and SSR23231 in the short arm of chromosome 3. Further investigation in 2013 revealed that the Ore locus is defined by the putative $\beta$-carotene hydroxylase 1 ; CsaBCH1 (Csa3G183920) gene. The Ore mutant contains a SNP in the conserved fatty acid hydroxylase domain of $\mathrm{CsaBCH} 1$ that disrupts $\beta$-carotene turnover, which is a substitution of alanine to asparagine at position 257 of the $B C H 1$ gene, encoding a $\beta$-carotene hydroxylase, and causes an accumulation of $\beta$-carotene in the Xishuangbanna group. This mutation results in a non-functional carotene hydroxylase, which is unable to convert carotene to zeaxanthin, resulting in a build-up of carotene [1,24].

Many other attempts have been made to study the regulations of $\beta$-carotene in orangefleshed cucumber cultivars. Other variants of cucumber with yellow flesh significantly contribute to $\beta$-carotene content. In 2015, an investigation of the yellow flesh color of cucumbers (line PI200815) discovered that the yellow mesocarp flesh color is controlled by a single recessive gene, yf, which is located on cucumber chromosome 7 [25]. A total of 12 SSR primers and 5 Indel markers were used to build a molecular marker linkage group and the closest flanking markers linked to yf were yf SSR108 and yf Indel29 with genetic distances of 0.6 and $0.3 \mathrm{cM}$, respectively. The physical distance between $y f$ and the area containing 21 projected candidate genes was $149.0 \mathrm{~kb}$. The latest study of XIS cucumber in 2019 on $\beta$-carotene content reported an identification of SNP in the homolog of the cauliflower Ore gene. This study however concluded that the Ore gene is not the only factor affecting $\beta$-carotene accumulation in orange flesh cucumber [26]. Other than $\beta$-carotene content, the QTL of the flowering and fruit physical qualitative traits have recently have also been reported $[27,28]$. A study involving a combination of genomics and transcriptomic further gave insights into photoperiod regulation of flowering in XIS cucumber [29]. 


\section{Research Achievements Derived from the Utilization of Orange-Fleshed Cucumber and Research Gaps}

\subsection{Agronomic Characteristics of Orange-Fleshed Cultivar and Associated QTL}

Growing cucumber solely for nutritional quality could be unsustainable among the farmers. However, nutrition coupled with desirable phenotypic characteristics would provide additional advantages. Germplasm adaptations and adoptions are defined by phenotypic qualities such as plant growth habit, blooming characteristics, fruit yield, and yield components.

\subsubsection{XIS Cucumber Vegetative Growth and Flowering Characteristics}

XIS cucumber has indeterminate growth habits. The main vine of XIS cucumber can reach up to $8 \mathrm{~m}$ in length, with 20-40 lateral branches and 900 nodes, which is faster than cucumbers grown commercially [10].

The flowering time of cucumber determines the time of fruit set, and hence affects the crop production cycle. Flowering in semi-wild XIS cucumber is complicated. Naturally, it is photoperiod-sensitive and requires short day conditions for the induction of female flowering [30], and this presents one of the major constraints to breeding and productivity of orange-fleshed XIS cucumber. Using populations derived from semi-wild XIS cucumber and cultivated cucumber, two QTL (fft1.1 and fft6.1) [27] and three QTL (FT1.1, FT5.1, FT6.2) [28] affecting female flowering time were detected. Recently, nuclear transcription factor Y A-1 (CsaNFYA1 Csa1G613580) a potential candidate gene defining DFF1.1, was reported [29]. CsaNFYA1 gene was found to have a single non-synonymous mutation in its fifth exon, based on whole-genome re-sequencing of nine cucumber cultivars with varied flowering characteristics in response to photoperiod.

\subsubsection{XIS Cucumber Fruit Quality Characteristics}

Cucumber fruit shape and size are essential quality factors because they influence yield and quality. Mature fruit shape/size of XIS cucumber vary considerably and they could be long, oblong, oval, or round and comprising a length to diameter ratio (L/D) from 1 to 4 [17]. The round fruit sets by XIS cucumber possessing five carpels resemble those of melon $[1,28]$. Using XIS cucumber inbred line WI7239 with round fruit shape, Two interacting genes, FS1.2 and FS2.1, that control fruit shape was detected [28]. Two consistent QTL were also obtained using SWCC8; an XIS inbred line (FS1.2, FS2.1) was unique to the SWCC8 or WI7167 population, but with three additional QTL (FS3.1, FS3.2, and FS5.2). This implies possible diversifying selection of fruit size and shape within the XIS cucumber population. Furthermore, since round fruit form is recessive to long fruit in the XIS cucumber population, 'round fruit shape' appears to be a more primitive feature.

Fruit length is also an important fruit quality trait influenced by QTL. A mature XIS cucumber has a fruit length to diameter ratio (L/D) of 1.5:1-3:1 and is shorter than that of a typical U.S. processing cucumbers (2.8:1 to 3.4:1) [10]. Fruit shape is frequently described using the fruit L/D ratio (also known as fruit shape index Five QTL for LD, namely, ld1.1, ld1.2, ld3.1, ld5.1, and ld6.1 have been reported [28] Because L/D is a compound trait governed by the L and D values, the locations of all five LD QTL were consistent with those of either mature fruit length (MFL) and mature fruit diameter (MFD) or both. Among the five L/D QTL, ld5.1 had the greatest LOD support (LOD > 40.0) and the greatest effect $(\mathrm{R} 2=36.7-51.0$ percent) in lowering the $\mathrm{L} / \mathrm{D}$ value (negative additive effects). This appears counter-intuitive given that neither mf5.1 nor mfd5.1 had the greatest impact. The significance of the consensus fruit size QTL FS5.2 (based on mf5.1, mfd5.1, and ld5.1) in determining round fruit shape was demonstrated by segregation analysis in the WI7200 and WI7167 $\mathrm{F}_{2}$ population [28]. Fruit weight is an important yield component. A mature XIS fruit weighs 2-3 kg (up to $5 \mathrm{~kg}$ ) and contains more than 1000 seeds. A major QTL fw6.1 (at $42.7 \mathrm{cM}$ and other minor QTL ( $\mathrm{fw} 4.1, \mathrm{fw} 2.1$ ) controlling XIS fruit weight have also been reported [27]. However, fine mapping of candidate genes of fw6.1 remains unidentified. 
Fruit flesh colour and flesh thickness variations are important attributes determining fruit quality. Recent progeny originating from the cross between Xishuangbanna, such as those from a cross between SWCC $8 \times C C 3$, has been witnessed with variation in the distribution of flesh color as well as the thickness and size of the endocarp (Figure 1). The progeny flesh color could either have white or yellow mesocarp and orange or yellow endocarp. The resulting progeny also varies considerably in terms of mesocarp and endocarp sizes. This consists of smaller mesocarp thickness and larger endocarp, or vice versa, and occasionally with hollow orange-fleshed endocarp at mature fruit stages. The mesocarp thickness range from 10 to $35 \mathrm{~mm}$, while the diameter of the endocarp of the orange-fleshed derived progeny ranges from 25 to $65 \mathrm{~mm}$. Fruit flesh thickness is an important trait for cucumber because it is a central determinant of yield [31]. The molecular mechanisms resulting in the variation in mesocarp thickness and size of the endocarp of orange-fleshed XIS lines await future studies.

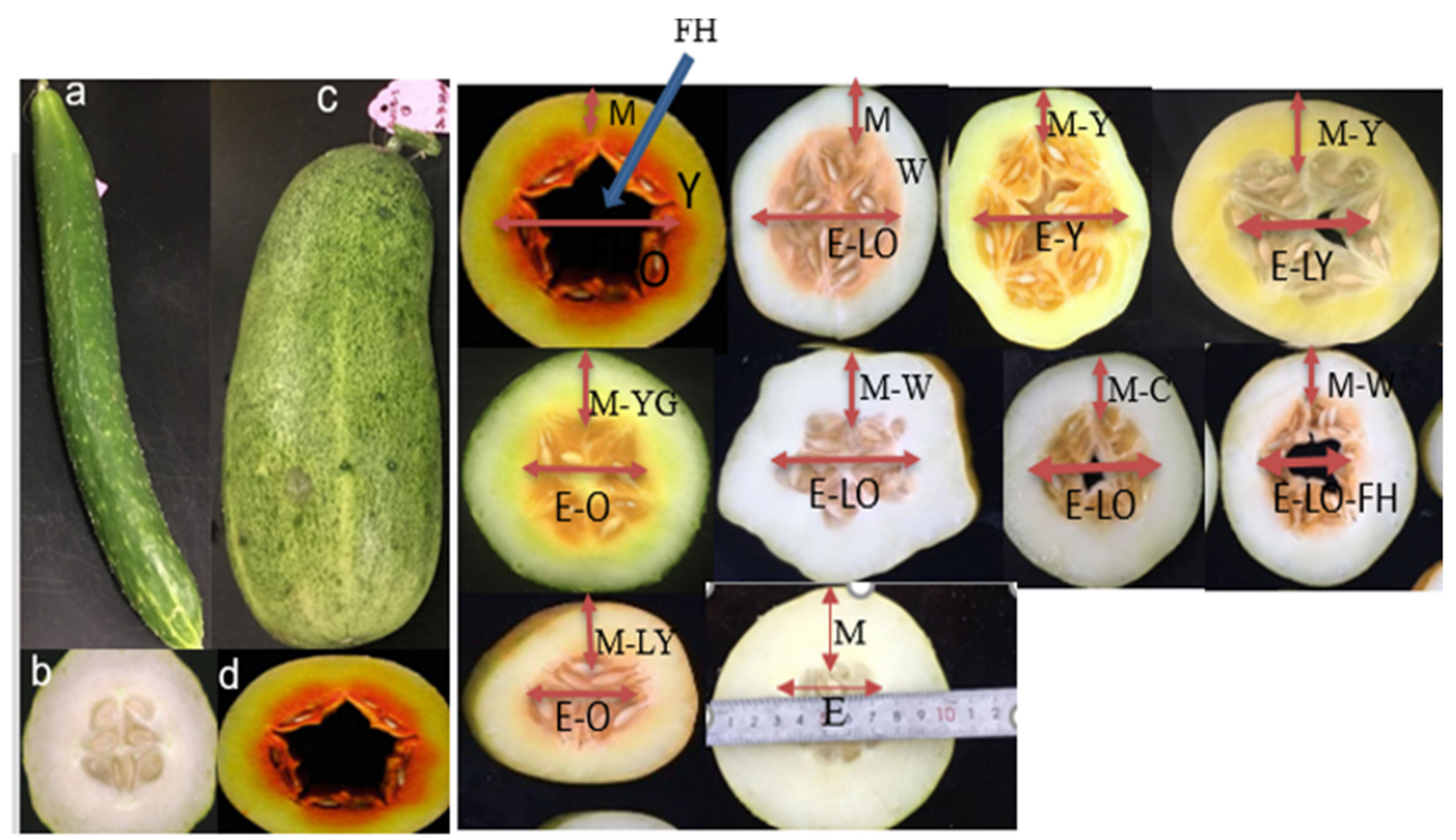

Figure 1. Morphological characteristics of (a) Chinese long inbred line and its (b) flesh color in comparison with (c) Xishuangbanna derived line and its (d) flesh color. Variation in mesocarp thickness, endocarp diameter, and the flesh colors of RIL-F ${ }_{9}\left(\mathrm{SWCC} 8{ }^{*} \mathrm{CC} 3\right)$ mesocarp $(\mathrm{M})$, endocarp $(\mathrm{E})$, orange $(\mathrm{O})$, yellow $(\mathrm{Y})$, light orange (LO), light yellow (LY), yellow green (YG), cream (C), white (W), and fruit hollowness (FH); RIL-F9 (recombinant filial 9; SWCC8- South West China cultivar; CC3 Chinese long inbred cultivar.

\subsection{Molecular Markers and QTL Analysis Related to Flesh Color and Quantity of $\beta$-Carotene Content in Cucumber}

\subsubsection{General Overview of Molecular Markers}

Molecular markers are sequences of deoxyribonucleic acid (DNA) that enable for the discovery of polymorphisms in specific DNA regions that exist among individuals in the population. Types of molecular markers include random amplified polymorphic DNA, restriction fragment length polymorphism, amplified fragment length polymorphism, microsatellite simple sequence lengths, and single nucleotide polymorphism. In gene mapping, molecular markers allow for the direct identification of the gene of interest rather than the gene product, making it a useful tool for screening somatic cell hybrids, aiding in the physical mapping of genes using in situ hybridization and used for linkage analysis to generate genetic maps [32]. 
With the advancement of molecular biotechnology, molecular markers have become important tools in breeding [33]. Because molecular markers occur in the form of DNA, there is no epistatic effect or other forms of gene interaction between non-allelic markers and molecular markers $[34,35]$. Furthermore, because polymorphism can be found almost everywhere in the genome, the molecular marker is reliable, reproducible, and stable. Gene mapping, gene cloning, genetic map development, systematic taxonomy, genetic germplasm resource research, and assisted selective breeding all use molecular markers [36,37]. Therefore, cucumber nutritional quality improvement could exploit the advantages of the previously identified molecular markers for marker assisted section (MAS). We summarized the identification of molecular markers and QTL of horticulturally important traits in XIS cucumber (Table 1).

Table 1. Quantitative trait loci (QTL) of Xishuangbanna cucumber fruit quality and flowering-related traits.

\begin{tabular}{|c|c|c|c|c|c|c|c|}
\hline Variable & $\begin{array}{l}\text { Breeding } \\
\text { Technique }\end{array}$ & Pop. & Chr. & QTL & Genes/Markers & $\begin{array}{l}\text { Predicted } \\
\text { Functions }\end{array}$ & Ref. \\
\hline Orange flesh & QTL mapping & $\mathrm{F}_{2}$ & $\begin{array}{l}6 \\
3\end{array}$ & $\begin{array}{l}\text { mc6.1/ec6. } \\
\text { mc3.1/ec3.1 }\end{array}$ & & & {$[20]$} \\
\hline \multirow{2}{*}{$\begin{array}{l}\beta \text {-carotene } \\
\text { (Endocarp) }\end{array}$} & $\begin{array}{l}\text { QTL (mapping) } \\
\text { (SSR markers) }\end{array}$ & RIL-F9, & 3 & ec3.1 & Ore gene & & [23] \\
\hline & Cloning & & 3 & ec3.1 & $\begin{array}{c}\text { CsBCH1 } \\
\text { (CsGy3G017310.1) }\end{array}$ & $\begin{array}{c}\beta \text {-carotene } \\
\text { hydroxylase }\end{array}$ & {$[1]$} \\
\hline $\begin{array}{l}\text { Yellow flesh } \\
\text { (Mesocarp) }\end{array}$ & $\begin{array}{l}\text { QTL (mapping) } \\
\text { SSR and indel }\end{array}$ & $\mathrm{F}_{2}$ & 7 & yf7.1 & $\begin{array}{c}\text { yfSSR108,yfIndel29), } \\
21 \text { predicted } \\
\text { candidate genes }\end{array}$ & & [25] \\
\hline $\begin{array}{l}\text { Round fruit } \\
\text { shape }\end{array}$ & QTL mapping & $\mathrm{F}_{2}, \mathrm{~F}_{2.3}$ & & FS5.2 & & & [28] \\
\hline Fruit diameter & QTL mapping & $\mathrm{F}_{2}$ & 1 & $\mathrm{fd} 1.1$ & & & {$[28,38]$} \\
\hline Fruit length & Mapping & $\mathrm{F}_{2}$ & $3,5,6$ & $\begin{array}{c}\mathrm{fl} 3.1, \\
\mathrm{fl} 5.1, \mathrm{fl} 6.1\end{array}$ & & - & $\begin{array}{l}{[38]} \\
{[27]} \\
{[28]}\end{array}$ \\
\hline $\begin{array}{c}\text { Length to } \\
\text { diameter ratio }\end{array}$ & QTL mapping & $\mathrm{F}_{2}$ & 1 & ldl1.1 & & & [28] \\
\hline Fruit weight & QTL & RIL-F9 & & $\begin{array}{c}\text { fw6.1, fw4.1, } \\
\text { fw2.1 }\end{array}$ & & & [27] \\
\hline $\begin{array}{l}\text { Photoperiod } \\
\text { flowering time }\end{array}$ & QTL mapping & $\mathrm{F}_{2}, \mathrm{~F}_{2.3}$ & 6 & FT6.1 & & & [28] \\
\hline $\begin{array}{l}\text { Male flowering } \\
\text { time }\end{array}$ & QTL mapping & $\mathrm{F}_{2}$ & $\begin{array}{l}1 \\
6\end{array}$ & $\begin{array}{l}\mathrm{mft} 1.1 \\
\mathrm{mft} 6.1\end{array}$ & & & $\begin{array}{l}{[38]} \\
{[28]}\end{array}$ \\
\hline $\begin{array}{l}\text { Female } \\
\text { flowering time }\end{array}$ & $\begin{array}{l}\text { QTL mapping } \\
\text { QTL, and } \\
\text { Transcriptomic }\end{array}$ & $\begin{array}{c}\mathrm{F}_{2} \\
\text { RIL-F9 }\end{array}$ & $\begin{array}{c}1,5,6 \\
1\end{array}$ & $\begin{array}{c}\mathrm{fft} 1.1 \\
\mathrm{fft} 5.1, \mathrm{fft} 6.2 \\
\text { dff1.1 }\end{array}$ & $\begin{array}{c}\text { CsaNFYA1 } \\
\text { (Csa1G613580) }\end{array}$ & $\begin{array}{l}\text { Integrate } \\
\text { multiple } \\
\text { gene }\end{array}$ & $\begin{array}{c}{[27,28,38]} \\
{[29]}\end{array}$ \\
\hline
\end{tabular}

Pop-population; Chr.-chromosome.

\subsubsection{Molecular Markers and QTL Analysis in XIS Cucumber}

A quantitative trait locus (QTL) is a genomic region that correlates with phenotypic variation of a quantitative trait. It helps to unfold phenotypic occurrence. QTL are discovered by determining which molecular markers are associated with a certain trait [39]. Several studies have shown the genetic and molecular mechanisms conferring the accumulation of $\beta$-carotene in orange-fleshed cucumbers. It is now commonly known that $\beta$-carotene is determined by quantitative trait loci (QTL), and that environmental conditions and other cellular transcription factors are likely to influence it.

Two $\mathrm{F}_{2}$ populations derived from parental lines with white flesh crossed to orange flesh (SWCC9' and USDA number 14 produced from XIS) were used for the determination of quantitative trait loci (QTL) analysis related to orange fruit flesh color [20]. Two genetic linkage maps were created using RAPD, SCAR, SSR, EST, SNP, AFLP, and SSAP markers to find a shared collinear region containing four molecular markers (3 dominant and 1 codominant) on linkage group (LG) LG6 in Map 1 and LG3 in Map 2 
to determine a shared collinear region containing four molecular markers (3 dominant and 1 codominant) on LG6 in Map 1 and LG3 in Map 2. In maps 1 and 2, there were QTL associated with orange mesocarp (mc)/endocarp (ec) color at these places (mc6.1/ec6.1) and (mc3.1/ec3.1). In mesocarp and endocarp tissue, biochemical studies revealed that $\beta$-carotene and xanthophyll (x) were the two most abundant carotenoids. QTL affecting endocarp carotene content (edb3.1) and mesocarp xanthophyll content (mdx3.1) in Map2 mapped to the same interval as mc3.1 and ec3.1, respectively. Furthermore, NCED (9-cisEpoxycarotenoid dioxygenase), a carotenoid biosynthesis gene, corresponded to the same interval in both maps as orange flesh color QTL (mc6.1/ec6.1 and mc3.1/ec3.1). The finding from this study suggested that the QTL on these regions should be investigated for use in marker-assisted selection of $\beta$-carotene gene introgression into commercial cucumber.

To explain the inheritance of orange mesocarp in cucumber, three gene model was proposed to explain the inheritance of orange mesocarp in cucumber [21] contrary to Navazio [19], who presented a single gene model approach. Other than the environment, the difference probably resulted from the population sizes used in each case [10] comprising $46 \mathrm{~F}_{2}$ progenies versus $111 \mathrm{~F}_{2}$ and $51 \mathrm{BC}_{1} \mathrm{P}_{2}$ progenies and/or the growing environment [21]. Using a large $\mathrm{F}_{2}$ population, a single recessive gene was found to be responsible for the regulation of the yellow flesh color [25]. The above genetic analysis indicated that the flesh color of XIS cucumber is mostly a qualitative trait, which suggests that the specific genes resulting in flesh color formation occurred during evolution and domestication. Two parents (P1, PI183967, P2, 9110Gt), their $\mathrm{F}_{1}$, three $\mathrm{F}_{2}$, one BC1P1, and one BC1P2 populations were used in five experiments over two years to study the inheritance of flesh extract color (FEC), green flesh color (FC) and flesh chlorophyll content (FCC) in cucumber [40] The FEC, FC, and FCC phenotypic data had a significant positive correlation for the same population in different experiments. The frequency distributions of FEC, FC, and FCC among the three $\mathrm{F}_{2}$ populations were bimodal rather than normal, especially for the FC and FEC, suggesting that green flesh color is controlled by a major QTL.

The first QTL mapping for cucumber carotenoid was published in 2012 [27] The Ore (orange endocarp) controlled by a single recessive gene was mapped on chromosome 3 and closely linked with seven SSR markers. The associated molecular markers linked to the Ore locus could be used in future cucumber $\beta$-carotene studies. PI200815, a cucumber that originated in Myanmar, is another cucumber with yellow flesh in the mature fruit stage. Kooistra, [41] discovered that the color of the flesh (which included orange, yellow, dingy white, and bright white) was controlled by two genes in a study of the inheritance of yellow fruit flesh in cucumbers. The initial mapping reported that yellow flesh is governed by a recessive gene, yf [25]. However, the aforementioned orange and yellow flesh hue only occurred in the mature stage, thus this is great challenge for normal utilization of cucumber. Further, the yf gene was delimited within a region of $149 \mathrm{~kb}$ on cucumber Chr. 7, and 21 predicted candidate genes were identified from the genomic map of cucumber. In plants, $\beta$-carotene synthesis is mainly governed by several genes: IPP isomerase, GGPP synthase, phytoene synthase (PSY), phytoene desaturase (PDS), zeta-carotene desaturase (ZDS), and lycopene-cyclase (LCYB) [42]. None of these genes were found to be located within the region of $149 \mathrm{~kb}$ on $\mathrm{Chr}$. 7. It is possible that the $\mathrm{yf}$ gene may be a regulatory factor of a functional gene in the $\beta$-carotene synthesis pathway, and the elucidation of this proposition will require further study. To the best of our knowledge, by the time of this review, no literature had reported genetic dissection of other fruit nutritive quality variables such as vitamin C, flavor, and sugar levels, among others.

\subsection{Regulation of Carotenoid Biosynthesis and Accumulation}

Expression of carotenoid pathway biosynthetic genes presents an alternative way through which carotenoid levels can be regulated. Expression levels of a plant phytoene synthase (PSY) and a phytoene desaturase (PDS), the first enzymes and rate limiting steps in the carotenoid synthesis pathway, are key contributors to $\beta$-carotene levels in plants and are known to be regulated by transcriptional factor families [43]. In model plants such as 
tomato, carotenoid accumulation is primarily determined by transcriptional regulation of carotenoid related genes in which distinct phases of the carotenoid biosynthesis process are individually silenced or increased $[44,45]$. Other than $\mathrm{CsaBCH} 1$, studies involved in the investigation of transcriptional regulation of XIS carotenogenesis have not been reported.

As previously stated, $\beta$-carotene accumulation in the XIS cucumber is linked to the loss of function of the $\mathrm{CsaBCH} 1$ gene, which is responsible for the conversion of $\beta$-carotene to downstream molecules. This non-synonymous polymorphism is found in the CsaBCH1 region that codes for the conserved domain (PF04116, the fatty acid hydroxylase domain). CsaBCH1 orthologs from other species were compared and it was discovered that the XIS group has an uncommon mutation that affects the gene's function [1]. However, further functional analyses including promoter analysis and gene silencing techniques of $\mathrm{CsaBCH} 1$ gene are still lacking in XIS cucumber. The mapping of carotenoid biosynthetic genes in the XIS cucumber, as well as their possible role in carotenoid biosynthesis, is a promising future research opportunity. The phase of chlorophyll-carotenoid transition in XIS occurs at least 30 days post flowering/pollination, thereafter the concentration increases exponentially, reaching a peak at 45-60 days after flowering [1]. Plastid development has been shown to have a distinct role in carotenogenesis in other crops such grapefruit [46] and tomato [47]. The change in flesh color is associated with chlorophyll-chromoplast transition. The role of the cucumber chloroplast-chromoplast transition in carotenoid accumulation in XIS remains unknown.

While $\beta$-carotene in XIS cucumber is linked to the Ore gene, it is believed that the OR protein that was first reported in cauliflower plays a major role in plastidial carotenoid flux. OR contains a Cys-rich zinc finger domain that is found in DnaJ chaperones. OR, on the other hand, lacks the J domain that characterizes this family of proteins [48]. OR proteins were found to interact directly and post-transcriptionally in Arabidopsis (Arabidopsis thaliana) to regulate PSY in the control of carotenoid production [49]. Overexpression of the Arabidopsis OR protein with a mutation (Arg to His) at the relevant region of the melon golden SNP led to high $\beta$-carotene levels [50]. The increase in $\beta$-carotene in these situations has been linked to chromoplast biogenesis [51]. While reports from a variety of other orange-fleshed crops have shown the role of OR in chromoplast differentiation and controls carotenoid level [52,53], certainly, similar mechanisms are expected to occur in XIS cucumber. Cucumber and melon show close genetic syntenic relationships [54]. According to previous reports, multiple melon accessions differing in the golden SNP, the regulation of PSY level, and activity is not the mechanism by which CmOr natural allelic variation governs fruit $\beta$-carotene levels in melon. They also reported that the golden SNP mutation had no effect on the rate of $\beta$-carotene synthesis. Chemicals and genetics of the carotenogenic flow resulted in the accumulation of carotenoids, independent of the golden SNP. As a result, $\mathrm{CmOr}$-His was proposed to stabilize $\beta$-carotene and prevent its turnover, potentially resulting in $\beta$-carotene accumulation and chromoplast production as a metabolite-derived process. Moreover, it has been hypothesized that Ore gene is not the only factor controlling $\beta$-carotene accumulation in XIS cucumber [28]. Thus, powerful interaction between genomics, population genetics, and experimental would further advance our knowledge on the molecular mechanism of this important trait.

\section{Future Prospects in Molecular Breeding of $\beta$-Carotene Content in Cucumber}

Based on the foregoing review, it is apparent that previous research on $\beta$-carotene accumulation in orange-fleshed cucumber has been explored through introgression of XIS with other cultivated cucumber species for the identification of QTL and related markers. However, more approaches for further insights into XIS cucumber could be tested, as summarized in this section (Figure 2). Rajasree and Pugalendhi [55] highlighted the modern nutritional breeding techniques with wider application in vegetable crops, and these include the following: mutation breeding [56], polyploidy breeding [57], biotechnological approaches, advanced backcross QTL analysis, and transgenic approaches [58]. Each approach has distinct or shared objectives in XIS cucumber. Given the relatively few QTL 
associated with XIS traits and their comparatively high allied LOD values, backcross MAS could be advantageous in the development of orange-colored, high $\beta$-carotene containing cucumber germplasm and other associated traits [20].

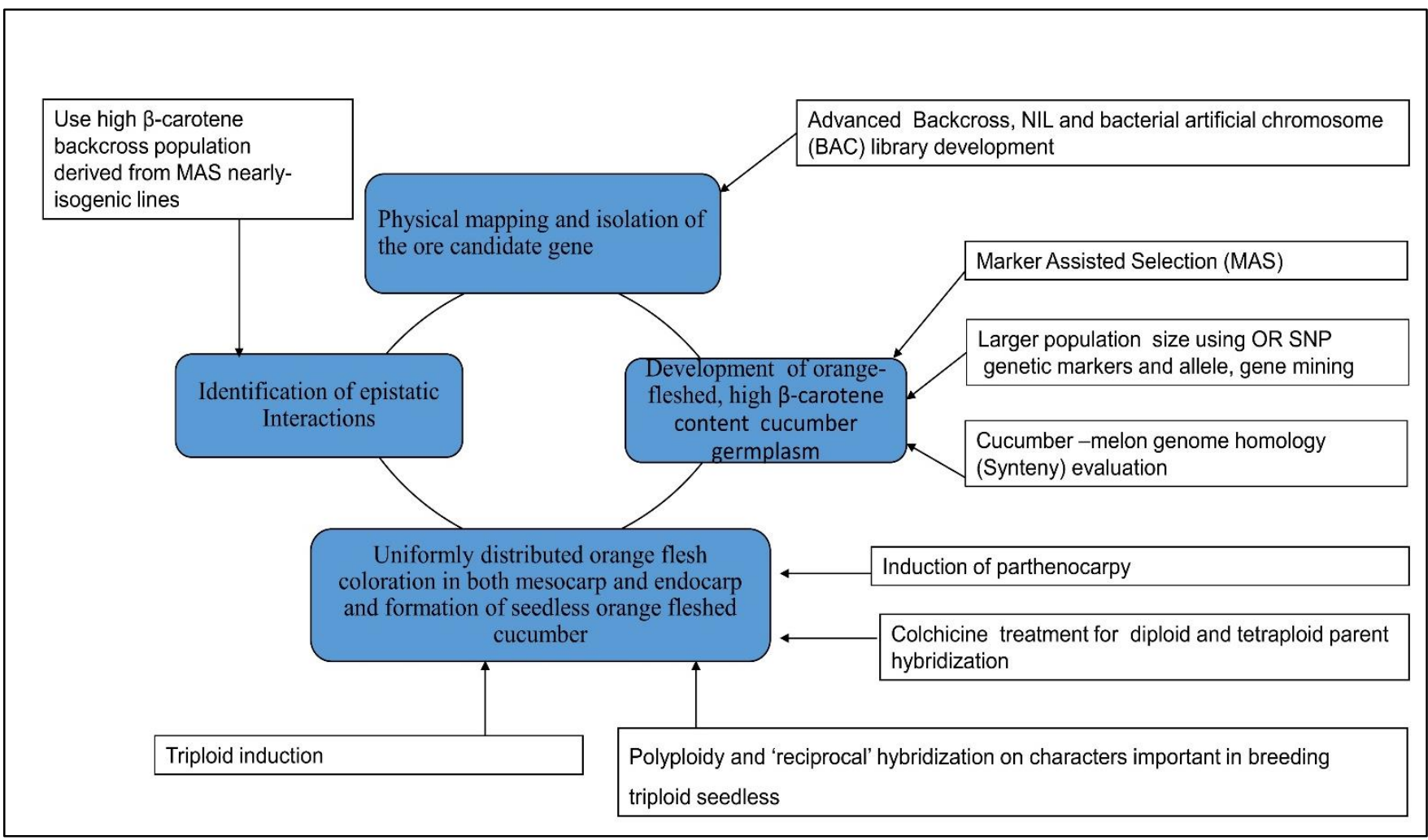

Figure 2. A summary of the proposed approaches to unravel the genetic basis of $\beta$-carotene accumulation in orange-/yellow-fleshed cucumber. The boxes highlighted in blue are the proposed main objectives, while the arrow points to the applicable methodology. Advanced backcross [21]; MAS [21,22,25]; OR SNP genetic markers [26]; Triploid induction [57]; cucumber-melon synteny [59,60]; parthenocarpy [61]; colchicine treatment [62]; polyploidy hy-bridization [63].

\subsection{Combined Omics and Gene Editing Technology for Carotenoid Improvement}

Combined 'omics' presents a powerful tool for molecular diagnosis of important qualitative and quantitative traits. Whereas the cucumber genome has been sequenced and released for the emergence of next generation sequencing technologies [64], genomics alone may not meet the demand of the researchers. With the rapid development of sequencing technology, many omics technologies, such as transcriptomics, proteomics, and metabolomics, have been developed [65] and applied in cucumber research. A large amount of data generated from these studies provides a potential reference for mining cucumber functional genes controlling carotenoid accumulation. The combination of genomics and classical genetics has become a highly strong technique for identifying candidate genes influencing essential features such as carotenoid accumulation.

Combined 'omics' involving transcriptomics, proteomics, and metabolomics has been used to further clarify the complex signal conversion mechanism of key regulatory genes in carotenoid accumulations [66]. Combining metabolite profiling with high-throughput RNA-sequencing analysis as well as proteomics established a correlation network between metabolites and genes involved in a number of important traits such as fruit flavor, fruit pigments, and other sensory characteristics in a number of crops. However, such studies are still lacking in dissecting the molecular mechanism of carotenoid biosynthesis in XIS cucumber. A number of regulators may be involved in those processes. Future studies should address the identification of key regulatory factors controlling the carotenoid 
metabolic pathway and chromoplast biogenesis. Genome editing research is currently being employed for plant research and crop improvement program [67]. By analyzing the differences between mutant and control plants, CRISPR/CAS9-mediated deletion and siRNA-mediated knockdown technologies can be utilized to identify the function of candidate genes [68]. Targeting of regulatory regions has been shown to alter gene expression without complete knockout of genes, leading to the development of useful traits. This is a current trend application for nutritional molecular breeding. For example, a comparison of the effects of mutations in the coding region to that of the $5^{\prime}$ untranslated region of CRTISO gene in tomato demonstrated that fruit quality changes can be achieved by CRISPR-Cas9based editing of CRTISO coding region [69] Further, a controlled knockdown of genes can be achieved by targeting the regulatory regions. In a similar study it was reported that colorrelated chlorophyll and carotenoid concentrations of Chinese kale can be altered through CRISPR/Cas9-targeted editing of the carotenoid isomerase gene, BoaCRTISO [70]. More specific and accurate modifications could be created at specific regulatory elements that are part of the untranslated sections or promoter regions of genes using modern technologies like "prime-editing", resulting in desired phenotypic features. These precise approaches could be used in cucumber improvement initiatives to increase $\beta$-carotene content.

\subsection{Candidate Gene Approach and Association Mapping Applications in Carotenoid Nutritional Improvement}

The candidate gene approach can systematically examine the relationship between structural genes in carotenoid biosynthetic pathway genes (PSY, PDS, ZDS, LCYB/LCYE, CHYB, VDE, ZEP, and NSY) and related phenotypic variability by using a comparative genetic system [71,72]. Comparative genetic maps, non-overlapping sets of mutants generated across plant species, could be more informative about the function and evolution of that locus than the allelic variability available in one species, which can be used to extend the candidate gene method to these features [73]. Furthermore, candidate genes for phenotypically defined quantitative and qualitative loci may be readily apparent for a wide range of species, providing new insights into cucumber $\beta$-carotene accumulation.

Association mapping targeting candidate genes has proven successful in many instances [74]. Therefore, this approach might bring new insights into carotenoid biosynthesis as the genetic pathway has already been dissected through forward and reverse genetics in many organisms. It addresses the relationship between marker-based polymorphism and phenotypic variation in a diversified population. In a diverse population, it examines the link between marker-based polymorphism and phenotypic variation. Using a diverse population and all ancestral recombination events may improve the resolution of such a study. In comparison with bi-parental cross, one of the key advantages of association mapping population is the ability to examine a large number of alleles [74].

\subsection{Manipulation of Hormonal and Environmental Cues Involved in the Regulation of Carotenoid Biosynthesis}

Molecular diagnosis and manipulation of hormonal and environmental factors might bring new insights into the mechanisms of carotenoid biosynthesis. Hormonal and environmental factors have been shown to influence carotenoid accumulation either directly on carotenoid synthesis genes or indirectly by acting on transcription factors involved in carotenoid biosynthesis $[75,76]$. Light and temperature are the key environmental factors regulating carotenoid biosynthesis [77]. The effects of plant hormones on carotenoid accumulation are well studied in tomato fruits. In addition, ethylene is an important hormone that plays a key role in regulating ripening-associated processes including carotenoid accumulation. Ripening inhibitor a master regulator of ethylene regulated fruit ripening, enhances lycopene accumulation during fruit ripening by positively regulating expression of PSY, PDS, ZDS, and CRTISO, and negatively regulating expression of LCYB and LCYE [78]. Therefore, studies elucidating the impact of these environmental factors on carotenoid accumulation in cucumber, particularly XIS cucumber, need future investigations. 
Structurally, fruits of XIS cucumber develop hollowness at the center of the endocarp, and this further limits the quantity of $\beta$-carotene derived from it by consumers. Moreover, it is the mesocarp that constitutes the greater percentage of the edible portion. Thus, developing a uniformly distributed orange-fleshed (mesocarp and endocarp) cucumber variety would be a greater milestone in carotenoid improvement. Such a novel cucumber variety would translate into the formation of a seedless cucumber similar to seedless watermelon. The known techniques of forming a seedless fruit comprise establishment of a parthenocarpic fruit or triploid development, as proposed herein, and hormonal or chemical treatments such auxins, ethylene, gibberellins or colchicine, among others [61-63,79].

\subsection{Application of Marker-Assisted Selection for $\beta$-Carotene Improvement and Development of Immature Orange-Fleshed Cucumber Variety}

Previously, the diallel analysis of immature fruit sizes demonstrated significant positive genetic combining ability for P101 (derived from XIS 'Addis'). Because orange color in immature cucumbers has not previously been detected in the most generally consumed stage of cucumbers, P101's capacity to express fruit pigmentation in size 2 (27-38 mm) fruit was a fortuitous and unexpected breakthrough in the breeding for carotenoid pigmentation [11]. The diallel study revealed that the parents had a high fruit carotene level. However, most diallel hybrids had a lower carotenoid content than their parents, indicating both low carotenoid content and a lack of genetic complementation among parents to improve fruit color. The genetic regulation of pigmentation in fruit with a diameter of $27-38 \mathrm{~mm}$ appeared to be separate from that of fruits with a diameter of $51-54 \mathrm{~mm}$. Although the carotene concentration in immature fruit was not quantified, the accumulation of $\beta$-carotene at this stage is regulated by many genes that have additive effects [11]. This allows for increased carotene content (orange color) through family selection. EOM 402-10 could be used to generate high-carotene pickled cucumbers with an orange endocarp/mesocarp that are appealing to customers thanks to their nutritional content. However, until now, no studies have further explored the genetic mechanism of orange coloration in immature EOM402-10 cucumber.

Genomics and marker assisted selection (MAS) technology has unlocked new pathways for improvement of complex quality traits $[60,80]$. Therefore, fully defined highcarotene $\mathrm{BC}_{2} \mathrm{~S}_{3}$ IBL produced by MAS and phenotypic selection could be used directly in epistatic interaction detection [63]. Additionally, the identification of XIS progeny line segregating for both ore and fft1.1 loci ('OreFt'), being $\beta$-carotene donor, can be used to foster $\beta$-carotene breeding initiatives. The $\beta$-carotene donor can then be instituted in the MAS by back crossing with inbred line segregating for fft1.1 locus (FFT), as outlined in Figure 3. One NIL study might look into the differences in fruit color orange hue and its dispersion observed in fruit developing in the field and greenhouse under long-day and short-day growth settings [10]. 


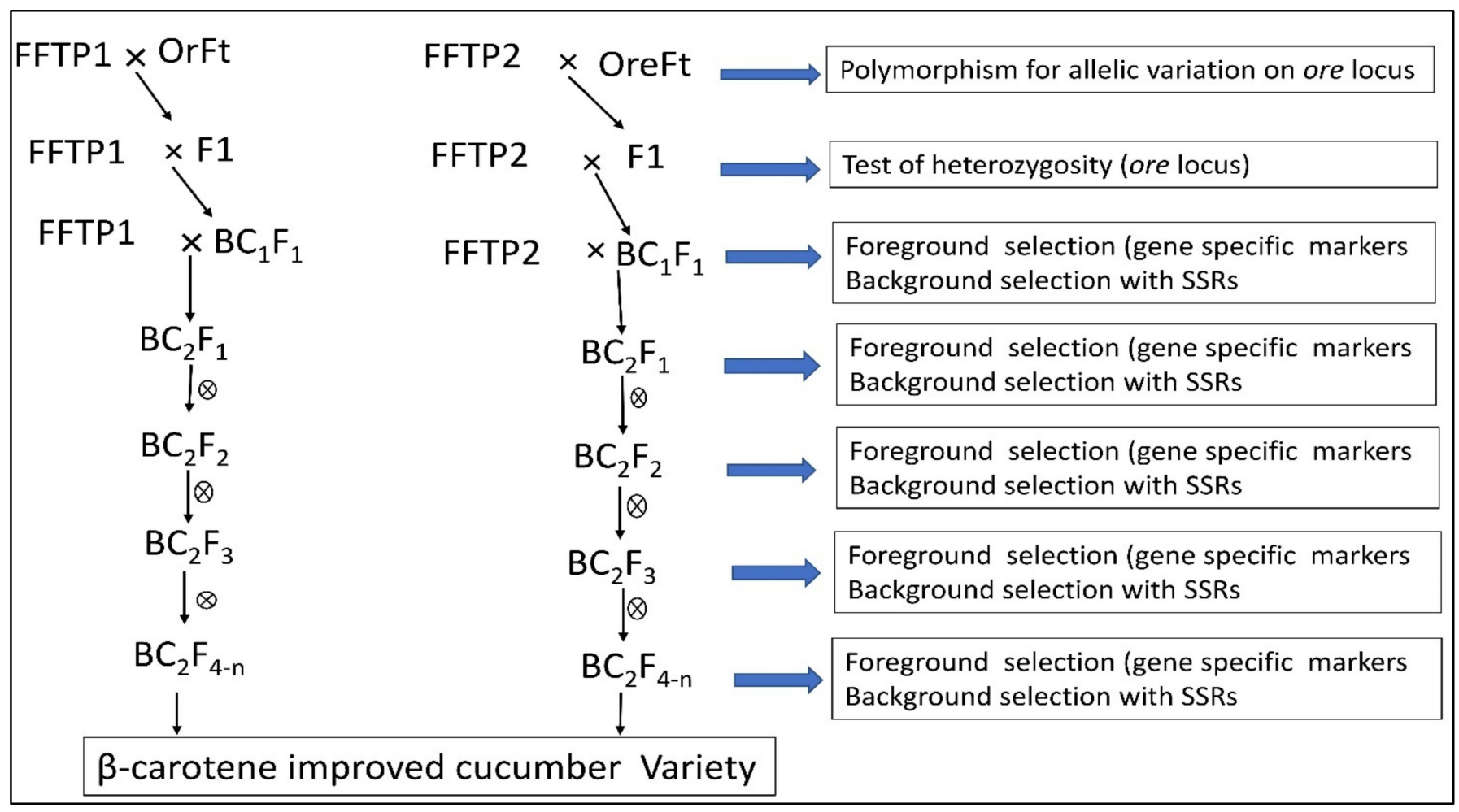

Figure 3. Marker assisted selection (MAS) strategy for utilization of ore recessive genes for development of an early flowering cucumber with enhanced $\beta$-carotene content. The phenotype description of above genes is based on the previous studies. OreFt, orange endocarp and early female flowering; $\mathrm{fft}$, first female flowering time; P1, parent 1; P2, parent 2, Selfing, $\otimes$.

\section{Conclusions}

Xishuangbanna cucumber provides a useful genetic resource for cucumber genetic improvement. XIS cucumber is predominantly recognized because of its high $\beta$-carotene content. $\beta$-carotene accumulation and regulation in fruits are affected by QTL, environmental factors, hormones, and transcription factor, among others. Beyond the nutritional benefits of $\beta$-carotene content, the striking orange flesh appearance of this commodity could attract consumer attention as a specialty crop either in processed or fresh state. Plant nutritional quality trait improvement has become a global necessity owing to the everincreasing world overpopulation and the demand for quality food One of the main goals of modern breeding projects is to produce agricultural species with improved nutrients and health-promoting properties, thus XIS cucumber could contribute in nutritional improvement programs. About half a century since the orange-fleshed cucumber was brought to the attention of horticulturists, many traits of agronomic importance other than $\beta$-carotene have been investigated. The quantitative trait loci related to flowering time, both female and male flowers, photoperiod response to flowering, and fruit quality characteristics (fruit size, weight, and shape) have been reported. However, fine mapping of the candidate genes regulating these traits remains a potential research area. Nevertheless, the identified QTL provide important clues for future fine mapping and cloning of the candidate genes. A significant molecular and germplasm improvement program can be used for rapid progress in cucumber nutritional breeding, including multiple germplasm and genetic collections, genetic engineering, marker assisted selection, and gene editing. We expect this review will appeal to the cucurbitaceous crop researchers and provide a reference for basic and applied research into XIS cucumber in the future.

Author Contributions: Conceptualization, J.C., J.O.O. and H.O.O.; methodology, H.O.O.; investigation, H.O.O., C.C. and Z.T.; resources, Q.L; writing—original draft preparation, H.O.O.; writing- 
review and editing, C.C., Z.T., J.L. and X.Y.; supervision, J.C., Q.L. and J.O.O.; project administration, Y.W.; funding acquisition, J.C. All authors have read and agreed to the published version of the manuscript.

Funding: This research was funded by National Key Research and Development Program of China (2020YFE0202900,2021YFD1200201), Asia Cooperation Fund Project-2021, the National Natural Science Foundation of China (31902007, 31902006), Jiangsu Belt and Road innovation cooperation project (BZ2019012), Jiangsu Agricultural Innovation of New Cultivars (PZCZ201719), and A Project Funded by the Priority Academic Program Development of Jiangsu Higher Education Institutions.

Institutional Review Board Statement: Not applicable.

Informed Consent Statement: Not applicable.

Data Availability Statement: Not applicable.

Acknowledgments: We are grateful for the technical support provided by the staff and members in the laboratory of cucurbit genetics and germplasm enhancement, College of Horticulture, Nanjing Agricultural University, China.

Conflicts of Interest: The authors declare no conflict of interest and The funders had no role in the design of the study; in the collection, analyses, or interpretation of data; in the writing of the manuscript; or in the decision to publish the results.

\section{References}

1. Qi, J.; Liu, X.; Shen, D.; Miao, H.; Xie, B.; Li, X.; Zeng, P.; Wang, S.; Shang, Y.; Gu, X.; et al. A genomic variation map provides insights into the genetic basis of cucumber domestication diversity. Nat. Genet. 2013, 45, 1510-1515. [CrossRef] [PubMed]

2. Chomicki, G.; Schaefer, H.; Renner, S.S. Origin domestication of Cucurbitaceae crops: Insights from phylogenies, genomics archaeology. New Phytol. 2020, 22, 1240-1255. [CrossRef] [PubMed]

3. Weng, Y. Cucumis sativus Chromosome Evolution, Domestication, Genetic Diversity: Implications for Cucumber Breeding. Plant Breed. Rev. 2021, 44, 79-111. [CrossRef]

4. Lv, J.; Qi, J.; Shi, Q.; Shen, D.; Zhang, S.; Shao, G.; Li, H.; Sun, Z.; Weng, Y.; Shang, Y.; et al. Genetic diversity population structure of cucumber (Cucumis sativus L.). PLoS ONE 2012, 7, e46919. [CrossRef]

5. Sharma, S.; Kumar, R.; Sharma, H.R.; Sharma, A.; Gautam, N. Divergence Studies for Different Horticultural Traits in Cucumber (Cucumis sativus L.). Int. J. Curr. Microbiol. Appl. Sci. 2018, 7, 1733-1741. [CrossRef]

6. Priyadarshini, M.; Das, S.; Muduli, K.C.; Mohanty, S.; Sahoo, S.; Pradhan, B.R. Characterization of cucumber genotypes through seed morphological characters. J. Pharm. Phytochem. 2012, 10, 2158-2161.

7. Butnariu, M.; Butu, A. Chemical composition of Vegetables their products. Handb. Food Chem. 2015, $20,627-692$.

8. Aderinola, T.A.; Abaire, K.E. Quality acceptability, nutritional composition antioxidant properties of carrot-cucumber juice. Beverages 2019, 5, 15. [CrossRef]

9. Available online: https://www.haifa-group.com/files/Guides/Cucumber.pdf (accessed on 11 January 2022).

10. Chen, J.F.; Zhang, S.L.; Zhang, X.G. The Xishuangbanna gourd (Cucumis sativus var. xishuangbannesis Qi et Yuan), a traditionally cultivated plant of the Hanai People, Xishuangbanna, Yunnan, China. Cucurbit Genet. Coop. Rpt. 1994, 17, 18-20.

11. Navazio, J.P.; Simon, P.W. Diallel analysis of high carotenoid content in cucumbers. J. Am. Soc. Hortic. Sci. 2001, 126, 100-104. [CrossRef]

12. Ranjan, P.; Pey, A.; Munshi, A.D.; Bhardwaj, R.; Gangopadhyay, K.K.; Malav, P.K.; Kumar, A. Orange-fleshed cucumber (Cucumis sativus var. sativus L.) germplasm from North-East India: Agro-morphological, biochemical evolutionary studies. Genet. Resour. Crop Evol. 2019, 66, 1217-1230. [CrossRef]

13. Renner, S.S. A valid name for the Xishuangbanna gourd, a cucumber with carotene-rich fruits. PhytoKeys 2017, 85, 87. [CrossRef]

14. Burger, Y.; Paris, H.S.; Cohen, R.; Katzir, N.; Tadmor, Y.; Lewinsohn, E.; Schaffer, A.A. 3 Genetic Diversity of Cucumis melo. Hort. Rev. 2010, 36, 165-198.

15. Wiseman, E.M.; Bar-El Dadon, S.; Reifen, R. The vicious cycle of vitamin a deficiency: A review. Crit. Rev. Food Sci. Nutri. 2017, 57, 3703-3714. [CrossRef]

16. Simon, P.W.; Navazio, J.P. Early orange mass 400, early orange mass 402, late orange mass 404: High $\beta$-carotene cucumber germplasm. Hort. Sci. 1997, 32, 144-145. [CrossRef]

17. Qi, C.Z.; Yuan, Z.Z.; Li, Y.X. A new type of cucumber-Xishuangbanna cucumber. Acta Hortic. Sin. 1983, 10, $259-264$.

18. Yang, S.L.; Pu, H.; Liu, P.Y. Preliminary studies on Cucumis sativus var. xishuangbannanesis. Cucurbit Genet. Coop. Rpt. 1991, 14, 29-31.

19. Navazio, J.P. Utilization of High $\beta$-Carotene Cucumber Germplasm for Genetic Improvement of Nutritional Quality. Ph.D. Thesis, University of Wisconsin, Madison, WI, USA, 1994. 
20. Staub, J. QTL analyses of orange color carotenoid content mapping of carotenoid biosynthesis genes in cucumber (Cucumis sativus L.). In Proceedings of the IV International Symposium on Cucurbits, Changsha, China, 21-26 September 2009; Volume 871, pp. 607-614.

21. Cuevas, H.E.; Song, H.; Staub, J.E.; Simon, P.W. Inheritance of $\beta$-carotene-associated flesh color in cucumber (Cucumis sativus L.) fruit. Euphytica 2010, 17, 301-311. [CrossRef]

22. Staub, J.E.; Simon, P.W.; Cuevas, H.E. Usda, Ars Eom 402-10 high $\beta$-carotene cucumber. Hortic. Sci. 2011, 46, 1426-1427. [CrossRef]

23. Bo, K.; Song, H.; Shen, J.; Qian, C.; Staub, J.E.; Simon, P.W.; Chen, J. Inheritance mapping of the Ore gene controlling the quantity of $\beta$-carotene in cucumber (Cucumis sativus L.) endocarp. Mol. Breed. 2012, 30, 335-344. [CrossRef]

24. Che, G.; Zhang, X. Molecular basis of cucumber fruit domestication. Curr. Opin. Plant Biol. 2019, 47, 38-46. [CrossRef]

25. Lu, H.W.; Miao, H.; Tian, G.L.; Wehner, T.C.; Gu, X.F.; Zhang, S.P. Molecular mapping cidate gene analysis for yellow fruit flesh in cucumber. Mol. Breed. 2015, 35, 64. [CrossRef]

26. Waters, B.M.; Kim, H.; Amundsen, K. New genetic sources for orange color in cucumber (Cucumis sativus L.) fruit flesh. bioRxiv 2019, 1, 685289.

27. Bo, K.; Ma, Z.; Chen, J.; Weng, Y. Molecular mapping reveals structural rearrangements quantitative trait loci underlying traits with local adaptation in semi-wild Xishuangbanna cucumber (Cucumis sativus L. var. xishuangbannanesis Qi et Yuan). Theor. Appl. Genet. 2015, 128, 25-39. [CrossRef] [PubMed]

28. Pan, Y.; Qu, S.; Bo, K.; Gao, M.; Haider, K.R.; Weng, Y. QTL mapping of domestication diversifying selection related traits in round-fruited semi-wild Xishuangbanna cucumber (Cucumis sativus L. var. xishuangbannanesis). Theor. Appl. Genet. 2017, 130, 1531-1548. [CrossRef] [PubMed]

29. Tian, Z.; Jahn, M.; Qin, X.; Obel, H.O.; Yang, F.; Li, J.; Chen, J. Genetic Transcriptomic Analysis Reveal the Molecular Basis of Photoperiod-Regulated Flowering in Xishuangbanna Cucumber (Cucumis sativus L. var. Xishuangbannesis Qi et Yuan). Genes 2021, 12, 1064. [CrossRef] [PubMed]

30. Bo, K.; Chen, L.; Qian, C.; Zhang, S.; Chen, J. Short-day treatments induce flowering of Xishuangbanna cucumber. China Cucurbits Veg. 2010, 23, 1-3.

31. Xu, X.; Lu, L.; Zhu, B.; Xu, Q.; Qi, X.; Chen, X. QTL mapping of cucumber fruit flesh thickness by SLAF-seq. Sci. Rep. 2015, 5, 15829. [CrossRef]

32. Garrido-Cardenas, J.A.; Mesa-Valle, C.; Manzano-Agugliaro, F. Trends in plant research using molecular markers. Planta 2018, 247, 543-557. [CrossRef]

33. Kage, U.; Kumar, A.; Dhokane, D.; Karre, S.; Kushalappa, A.C. Functional molecular markers for crop improvement. Crit. Rev. Biotechnol. 2016, 36, 917-930. [CrossRef]

34. Ahmad, F.; Akram, A.; Farman, K.; Abbas, T.; Bibi, A.; Khalid, S.; Waseem, M. Molecular Markers Marker Assisted Plant Breeding. Current Status their Applications in Agricultural Development. J. Environ. Agric. Sci. 2017, 11, 35-50.

35. Feng, S.; Zhang, J.; Mu, Z.; Wang, Y.; Wen, C.; Wu, T.; Wang, H. Recent progress on the molecular breeding of (Cucumis sativus L.) in China. Theor. Appl. Genet. 2020, 133, 1777-1790. [CrossRef]

36. Yan, J.B.; Tang, H.; Huang, Y.Q.; Zheng, Y.L.; Li, J.S. Quantitative trait loci mapping epistatic analysis for grain yield and yield components using molecular markers with an elite maize hybrid. Euphytica 2006, 149, 121-131. [CrossRef]

37. Hu, J.B.; Zhou, X.Y.; Li, J.W. Development of novel EST-SSR markers for cucumber (Cucumis sativus) their transferability to related species. Sci. Hortic. 2010, 125, 534-538. [CrossRef]

38. Qu, S.P.; Pan, Y.P.; Weng, Y.I.Q.U.N. QTL Mapping of flowering time and fruit shape in Xishuangbana cucumber (Cucumis sativus L. var. xishuangbannanesis Qi et Yuan). In Proceedings of the Cucurbitaceae, East Lansing, MI, USA, 21-26 October 2014; Volume 2014, pp. 54-56.

39. Asins, M.J. Present future of quantitative trait locus analysis in plant breeding. Plant Breed. 2002, 121, 281-291. [CrossRef]

40. Bo, K.; Wei, S.; Wang, W.; Miao, H.; Dong, S.; Zhang, S.; Gu, X. QTL mapping genome-wide association study reveal two novel loci associated with green flesh color in cucumber. BMC Plant Biol. 2019, 19, 243. [CrossRef]

41. Kooistra, E. Inheritance of fruit flesh skin colors in powdery mildew resistant cucumbers (Cucumis sativus L.). Euphytica 1997, 20, 521-523. [CrossRef]

42. Cunningham, F.X., Jr.; Gantt, E. Genes enzymes of carotenoid biosynthesis in plants. Annu. Rev. Plant Biol. 1998, 49, 557-583. [CrossRef]

43. Cazzonelli, C.I.; Pogson, B.J. Source to sink: Regulation of carotenoid biosynthesis in plants. Trends Plant Sci. 2010, 15, 266-274. [CrossRef]

44. Lado, J.; Zacarías, L.; Rodrigo, M.J. Regulation of carotenoid biosynthesis during fruit development. Carotenoids Nat. 2016, 79, 161-198. [CrossRef]

45. Sun, T.; Li, L. Toward the 'golden' era: The status in uncovering the regulatory control of carotenoid accumulation in plants. Plant Sci. 2020, 290, 110331. [CrossRef]

46. Lado, J.; Zacarías, L.; Gurrea, A.; Page, A.; Stead, A.; Rodrigo, M.J. Exploring the diversity in Citrus fruit coloration to decipher the relationship between plastid ultrastructure carotenoid composition. Planta 2015, 242, 645-661. [CrossRef]

47. Li, L.; Yuan, H. Chromoplast biogenesis carotenoid accumulation. Arch. Biochem. Biophys. 2013, 539, 102-109. [CrossRef]

48. Giuliano, G.; Tavazza, R.; Diretto, G.; Beyer, P.; Taylor, M.A. Metabolic engineering of carotenoid biosynthesis in plants. Trends Biotechnol. 2008, 26, 139-145. [CrossRef] 
49. Zhou, X.; Welsch, R.; Yang, Y.; Álvarez, D.; Riediger, M.; Yuan, H.; Li, L. Arabidopsis OR proteins are the major posttranscriptional regulators of phytoene synthase in controlling carotenoid biosynthesis. Proc. Natl. Acad. Sci. USA 2015, 11, 3558-3563. [CrossRef]

50. Yuan, H.; Owsiany, K.; Sheeja, T.; Zhou, X.; Rodriguez, C.; Li, Y.; Welsch, R.; Chayut, N.; Yang, Y.; Thannhauser, T.W.; et al. A single amino acid substitution in an ORANGE protein promotes carotenoid overaccumulation in Arabidopsis. Plant Physiol. 2015, 169, 421-431. [CrossRef]

51. Lu, S.; Van Eck, J.; Zhou, X.; Lopez, A.B.; O’Halloran, D.M.; Cosman, K.M.; Li, L. The cauliflower or gene encodes a DnaJ cysteine-rich domain-containing protein that mediates high levels of $\beta$-carotene accumulation. Plant Cell 2006, 18, $3594-3605$. [CrossRef]

52. Tzuri, G.; Zhou, X.; Chayut, N.; Yuan, H.; Portnoy, V.; Meir, A.; Sa'Ar, U.; Baumkoler, F.; Mazourek, M.; Lewinsohn, E.; et al. A 'golden' SNP in CmOr governs the fruit flesh color of melon (Cucumis melo). Plant J. 2015, 82, 267-279. [CrossRef]

53. Chayut, N.; Yuan, H.; Ohali, S.; Meir, A.; Sa'ar, U.; Tzuri, G.; Tadmor, Y. Distinct mechanisms of the ORANGE protein in controlling carotenoid flux. Plant Physiol. 2017, 173, 376-389. [CrossRef]

54. Chayut, N.; Yuan, H.; Ohali, S.; Meir, A.; Sa'Ar, U.; Tzuri, G.; Zheng, Y.; Mazourek, M.; Gepstein, S.; Zhou, X.; et al. Syntenic relationships between cucumber (Cucumis sativus L.) melon (C. melo L.) chromosomes as revealed by comparative genetic mapping. BMC Genom. 2011, 12, 376-389. [CrossRef]

55. Rajasree, V.; Pugalendhi, L. Breeding Vegetables for Nutritional Security. In Veganism-A Fashion Trend or Food as a Medicine; IntechOpen: London, UK, 2021.

56. Sapir, M.; Oren-Shamir, M.; Ovadia, R.; Reuveni, M.; Evenor, D.; Tadmor, Y.; Nahon, S.; Shlomo, H.; Chen, L.; Meir, A.; et al. Molecular aspects of Anthocyanin fruit tomato in relation to high pigment-1. J. Hered. 2008, 99, 292-303. [CrossRef] [PubMed]

57. Zhang, W.; Hao, H.; Ma, L.; Zhao, C.; Yu, X. Tetraploid muskmelon alters morphological characteristics improves fruit quality. Sci. Hortic. 2010, 125, 396-400. [CrossRef]

58. Singh, J.; Sharma, S.; Kaur, A.; Vikal, Y.; Cheema, A.K.; Bains, B.K.; Hossain, F. Marker-assisted pyramiding of lycopene- $\varepsilon$-cyclase, $\beta$-carotenehydroxylase1 opaque2 genes for development of biofortified maize hybrids. Sci. Rep. 2021, 11, 12642. [CrossRef] [PubMed]

59. Robbins, M.D.; Casler, M.; Staub, J.E. Pyramiding QTL for multiple lateral branching in cucumber using nearly isogenic lines. Mol. Breed. 2008, 22, 131-139. [CrossRef]

60. Staub, J.E.; Sun, Z.; Chung, S.M.; Lower, R.L. Evidence for collinearity among genetic linkage maps in cucumber. Hortic. Sci. 2007, $42,20-27$.

61. Kim, J.S.; Ezura, K.; Lee, J.; Ariizumi, T.; Ezura, H. Genetic engineering of parthenocarpic tomato plants using transient SIIAA9 knockdown by novel tissue-specific promoters. Sci. Rep. 2019, 9, 18871. [CrossRef]

62. Marzougui, N.; Boubaya, A.; Elfalleh, W.; Ferchichi, A.; Beji, M. Polyploidy induction in Trigonella foenum-graecum L.: Morphological chemical comparison between diploids induced autotetraploids cultivars. Acta Bot. Gall. 2009, 156, 379-389. [CrossRef]

63. Mason, A.S. Polyploidy Hybridization for Crop Improvement; CRC Press: Boca Raton, FL, USA, 2017.

64. Huang, S.; Li, R.; Zhang, Z.; Li, L.; Gu, X.; Fan, W.; Lucas, W.J.; Wang, X.; Xie, B.; Ni, P.; et al. The genome of the cucumber, Cucumis sativus L. Nat. Genet. 2009, 41, 1275-1281. [CrossRef]

65. Kumar, A.; Anju, T.; Kumar, S.; Chhapekar, S.; Sreedharan, S.; Singh, S.; Choi, S.; Ramchiary, N.; Lim, Y.P. Integrating Omics Gene Editing Tools for Rapid Improvement of Traditional Food Plants for Diversified Sustainable Food Security. Int. J. Mol. Sci. 2021, 22, 8093. [CrossRef]

66. Brunetti, A.E.; Neto, F.C.; Vera, M.C.; Taboada, C.; Pavarini, D.P.; Bauermeister, A.; Lopes, N.P. An integrative omics perspective for the analysis of chemical signals in ecological interactions. Chem. Soc. Rev. 2018, 47, 1574-1591. [CrossRef]

67. Perez-De-Castro, A.M.; Vilanova, S.; Canizares, J.; Pascual, L.; Blanca, J.; Diez, M.J.; Prohens, J.; Pico, B. Application of genomic tools in plant breeding. Curr. Genom. 2012, 13, 179-195. [CrossRef]

68. Saha, S.K.; Saikot, F.K.; Rahman, M.S.; Jamal, M.A.H.M.; Rahman, S.K.; Islam, S.R.; Kim, K.H. Programmable molecular scissors: Applications of a new tool for genome editing in biotech. Mol. Ther. Nucleic Acids 2019, 14, 212-238. [CrossRef]

69. Jayaraj, K.L.; Thulasidharan, N.; Antony, A.; John, M.; Augustine, R.; Chakravartty, N.; Sukumaran, S.; Maheswari, M.U.; Abraham, S.; Thomas, G.; et al. Targeted editing of tomato carotenoid isomerase reveals the role of $5^{\prime}$ UTR region in gene expression regulation. Plant Cell Rep. 2021, 40, 621-635. [CrossRef]

70. Sun, B.; Jiang, M.; Zheng, H.; Jian, Y.; Huang, W.L.; Yuan, Q.; Tang, H.R. Color-related chlorophyll carotenoid concentrations of Chinese kale can be altered through CRISPR/Cas9 targeted editing of the carotenoid isomerase gene BoaCRTISO. Hortic. Res. 2020, 7, 161. [CrossRef]

71. Thorup, T.A.; Tanyolac, B.; Livingstone, K.D.; Popovsky, S.; Paran, I.; Jahn, M. Cidate gene analysis of organ pigmentation loci in the Solanaceae. Proc. Natl. Acad. Sci. USA 2000, 97, 11192-11197. [CrossRef]

72. Guzman, I.; Hamby, S.; Romero, J.; Bosl, P.W.; O'Connell, M.A. Variability of carotenoid biosynthesis in orange colored Capsicum spp. Plant Sci. 2010, 179, 49-59. [CrossRef]

73. Cao, J.; Schneeberger, K.; Ossowski, S.; Günther, T.; Bender, S.; Fitz, J.; Weigel, D. Whole-genome sequencing of multiple Arabidopsis thaliana populations. Nat. Genet. 2011, 43, 956-963. [CrossRef]

74. Weber, A.; Clark, R.M.; Vaughn, L.; Sánchez-Gonzalez, J.D.J.; Yu, J.; Yandell, B.S.; Bradbury, P.; Doebley, J. Major regulatory genes in maize contribute to sting variation in teosinte (Zea mays ssp. parviglumis). Genetics 2011, 177, 2349-2359. [CrossRef] 
75. Ahmed, F.; Fanning, K.; Netzel, M.; Schenk, P.M. Induced carotenoid accumulation in Dunaliella salina Tetraselmis suecica by plant hormones UV-C radiation. Appl. Microbiol. Biotechnol. 2015, 99, 9407-9416. [CrossRef]

76. Stanley, L.; Yuan, Y.W. Transcriptional regulation of carotenoid biosynthesis in plants: So many regulators, so little consensus. Front. Plant Sci. 2019, 10, 1017. [CrossRef]

77. Pizarro, L.; Stange, C. Light-dependent regulation of carotenoid biosynthesis in plants. Cienc. E Investig. Agrar. 2009, 36, 143-162. [CrossRef]

78. Martel, C.; Vrebalov, J.; Tafelmeyer, P.; Giovannoni, J.J. The tomato MADS-box transcription factor Ripening Inhibitor interacts with promoters involved in numerous ripening processes in a Colorless Non-ripening dependent manner. Plant Physiol. 2011, 157, 1568-1579. [CrossRef]

79. Pandolfini, T. Seedless fruit production by hormonal regulation of fruit set. Nutrients 2009, 1, 168-177. [CrossRef]

80. Hasan, N.; Choudhary, S.; Naaz, N.; Sharma, N.; Laskar, R.A. Recent advancements in molecular marker-assisted selection applications in plant breeding programmes. J. Genet. Eng. Biotechnol. 2021, 19, 128. [CrossRef] 